Article

\title{
Comparative Antioxidant, Anti-Acetylcholinesterase and Anti- $\alpha$-Glucosidase Activities of Mediterranean Salvia Species
}

\author{
Mateja Mervić, Maja Bival Štefan, Marija Kindl, Biljana Blažeković, Marijan Marijan \\ and Sanda Vladimir-Knežević *
}

Citation: Mervić, M.; Bival Štefan, M.; Kindl, M.; Blažeković, B.; Marijan, M.; Vladimir-Knežević, S. Comparative Antioxidant, Anti-

Acetylcholinesterase and Anti- $\alpha$-Glucosidase Activities of Mediterranean Salvia Species. Plants 2022, 11, 625. https://doi.org/ 10.3390/plants11050625

Academic Editors: Rodica-Mihaela Dinică, Bianca Furdui and Antonella Smeriglio

Received: 31 December 2021 Accepted: 21 February 2022 Published: 25 February 2022

Publisher's Note: MDPI stays neutral with regard to jurisdictional claims in published maps and institutional affiliations.

Copyright: (C) 2022 by the authors. Licensee MDPI, Basel, Switzerland. This article is an open access article distributed under the terms and conditions of the Creative Commons Attribution (CC BY) license (https:// creativecommons.org/licenses/by/ $4.0 /)$.
Department of Pharmacognosy, Faculty of Pharmacy and Biochemistry, University of Zagreb, Trg Marka Marulića 20, 10000 Zagreb, Croatia; mmervic@pharma.hr (M.M.); mbival@pharma.hr (M.B.Š.); mkindl@pharma.hr (M.K.); bblazekovic@pharma.hr (B.B.); mmarijan@pharma.hr (M.M.)

* Correspondence: svladimir@pharma.hr

\begin{abstract}
Salvia species have a cosmopolitan distribution and comprise several well-known plants valuable for pharmaceutical and food industries due to their recognized medicinal, food flavouring, and preservative properties. The present study aimed to evaluate and compare the biological activities of seven wild-growing Salvia species from the Mediterranean area (S. fruticosa, S. glutinosa, S. nemorosa, S. officinalis, S. pratensis, S. sclarea, S. verticillata). All studied ethanolic leaf extracts exhibited significant $\mathrm{DPPH}$ and NO radical scavenging ability, lipid peroxidation inhibition, and reducing power, as well as moderate iron-chelating properties. Together with S. officinalis and S. fruticosa, S. verticillata showed anti-acetylcholinesterase activity, while S. glutinosa was also found to possess the ability to inhibit $\alpha$-glucosidase. Total flavonoid (0.37-0.90\%), phenolic acid (3.55-12.44\%), tannin $(1.22-2.60 \%)$, and anthocyanin contents $(0.03-0.08 \%)$ were determined in Salvia leaves. Rosmarinic acid was the predominant hydroxycinnamic acid in all studied sage plants, ranging from 9400 to $38,800 \mu \mathrm{g} / \mathrm{g}$. The correlation study showed a strong relationship between biological activities and contents of total phenolic acids, total tannins, and rosmarinic acid, indicating their significant contribution to the efficiency of tested Salvia species. Our results highlighted Mediterranean sage plants as rich sources of potent antioxidant, neuroprotective, and hypoglycemic agents which are worthy of further research.
\end{abstract}

Keywords: Salvia species; polyphenols; rosmarinic acid; antioxidant activity; acetylcholinesterase inhibition; $\alpha$-glucosidase inhibition

\section{Introduction}

Salvia L. is the largest genus of the Lamiaceae family. It comprises approximately 1000 species and has a cosmopolitan distribution. The main speciation centres of these taxa are Central and South America, Central Asia and the Mediterranean region, and East Asia. The genus Salvia includes annual, biennial, and perennial herbs, and woody subshrubs that exhibit remarkable diversity in growth forms, floral morphology, pollination biology and secondary metabolites [1,2]. Salvia species, commonly known as sage, are useful plants which have not lost their importance since ancient times. Some of them, such as S. officinalis L. (Dalmatian sage, common sage), S. lavandulifolia Vahl (Spanish sage), S. sclarea L. (clary sage), S. fruticosa Mill. (Greek sage), S. miltiorrhiza Bunge (danshen) and S. hispanica L. (chia), are cultivated worldwide for use in the pharmaceutical and food industries [3,4]. The main secondary metabolites of Salvia species are terpenoids and polyphenols. They are a rich source of essential oils with large contents of $\alpha$ - and $\beta$-thujone, camphor, $1,8-$ cineole, $\alpha$-humulene, $\beta$-caryophyllene, and viridiflorol. Diterpenes and triterpenes, such as carnosol, carnosic acid, tanshinones, and ursolic acid, are also very abundant compounds. The most representative flavonoids in the sage plants are the flavones apigenin and luteolin, their corresponding 6-hydroxylated derivatives, and flavonols. Caffeic acid present in various Salvia species is the building block of several metabolites from simple monomers to 
oligomers. The most abundant caffeic acid dimer identified in sage plants is rosmarinic acid, while lithospermic and salvianolic acids, sagecoumarin and yunnaneic acids are predominant among trimers derived from caffeic acid [5-7]. Previous research revealed the extensive biological effects of Salvia species, including antimicrobial, antioxidant, antiinflammatory, neuroprotective, and anticancer activities, among others [7-10].

The plants of the genus Salvia are widespread in tropical and temperate regions of Europe around the Mediterranean area to which Croatia belongs [8]. Croatian flora comprises 19 Salvia taxa, one of which is endemic [11]. The important representative of the genus Salvia in Croatian flora is S. officinalis L. It is an aromatic perennial subshrub, with woody stems, greenish-grey leaves, and rosy to violet-blue flowers, native to the Mediterranean shores [12,13]. Dalmatian sage is one of the most commercially important species within the mint family known for its richness in essential oils and its wide range of healing properties. The sage leaf (Salviae officinalis folium) is officially recognized as the herbal drug for the relief of inflammations in the mouth or the throat, mild dyspeptic complaints, excessive sweating, and minor skin inflammations [14]. In addition, S. officinalis has been used for a long time in food preparation due to its spicy, appetizing, digestive, and food preservative properties. It is considered as GRAS (Generally Recognized as Safe) for use as a spice and other natural seasonings and flavourings based on the Food and Drug Administration $[15,16]$.

Essential oils, non-volatile terpenes, flavonoids, and phenolic acids are proven to be the main active principles of $S$. officinalis that greatly contribute to its pharmacological properties $[6,16,17]$. The composition of essential oils can vary widely, but the major components are mostly oxygenated monoterpenoids $\alpha$-thujone, 1,8-cineole, and camphor [12,18]. Diterpenes and triterpenes (carnosic acid, carnosol, and ursolic acid) are also found to be present in Dalmatian sage $[19,20]$. The most prevalent flavonoids include glycosides of luteolin, apigenin, hispidulin, and quercetin [21-23]. Rosmarinic, salvianolic, caffeic and sagerinic acids, and sagecoumarin are abundant phenolic acids of S. officinalis [23]. In recent years, many studies have been conducted to prove traditionally claimed applications of $S$. officinalis and to discover new therapeutic properties of this plant. These studies revealed a wide range of pharmacological activities including antioxidant, anti-inflammatory, antimicrobial, anticancer, antimutagenic, hypoglycemic, antinociceptive, memory-enhancing, and hypolipidemic effects. Moreover, the last three listed have been demonstrated with clinical trials [16].

Along with S. officinalis, the important representatives of the genus Salvia wild growing in Croatia are S. fruticosa Mill., S. glutinosa L., S. nemorosa L., S. pratensis L., S. sclarea L., and S. verticillata L., which have not yet been sufficiently investigated. Due to the lack of scientific evidence, the present study aimed to evaluate the antioxidant, neuroprotective, and antidiabetic potential of the ethanolic extracts of selected Salvia species in comparison with S. officinalis as the most studied among the sage plants. The research focused specifically on plant polyphenolic constituents that exhibit strong antioxidant properties and have the potential to be used as dietary and therapeutic agents and food preservatives.

\section{Materials and Methods}

\subsection{Chemicals}

HPLC grade acetonitrile and o-phosphoric acid were provided by VWR Chemicals (Fontenay-sous-Bois, France). Acetylcholinesterase from electric eels and acetylthiocholine iodide (>98\%), $\alpha$-glucosidase from Saccharomyces cerevisiae (Type I, $>10 \mathrm{U} / \mathrm{mg}$ protein), 2-amino-2-(hydroxymethyl)propane-1,3-diol (Tris base), $p$-anisaldehyde, brain extract from bovine brain, chlorogenic acid (95\%), $p$-coumaric acid (98\%), 2,2-diphenyl1-picrylhydrazyl (DPPH), 5,5'-dithiobis-2-nitrobenzoic acid (DTNB, $>98 \%$ ), hide powder, phosphate buffer saline, 4-nitrophenyl- $\alpha$-D-glucopyranoside (>99\%), pyrogallol (99\%), rosmarinic acid $(97 \%)$, sodium molybdate, sodium nitrite, sulphanilamide, thiobarbituric acid, and trichloroacetic acid were purchased from Sigma-Aldrich (St. Louis, MO, USA). Trolox (>98\%), 3-(2-pyridyl)-5,6-diphenyl-1,2,4-triazine- $4^{\prime}, 4^{\prime \prime}$-disulfonic acid sodium salt 
(ferrozine), butylhydroxytoluene (BHT), caffeic acid (>95\%), ferulic acid (>98\%), and N-(1naphthyl)ethylenediamine dihydrochloride were provided by Fluka (Buchs, Switzerland). Acarbose ( $>98 \%$ ) and $\alpha / \beta$-thujone were provided by TCI (Tokyo, Japan). Aluminum chloride hexahydrate, disodium hydrogen phosphate dihydrate, ethylenediaminetetraacetic acid disodium salt (EDTA), formic acid, hexamethylenetetramine, iron(II) sulphate heptahydrate, sodium dihydrogen phosphate dihydrate, and sodium sulphate were obtained from Kemika (Zagreb, Croatia). Acetone, dimethyl sulfoxide, ethanol, and sodium carbonate decahydrate were purchased from Gram-Mol (Zagreb, Croatia). Acetic acid and sodium hydroxide were provided by Carlo Erba (Rodano, Italy). Ascorbic acid and phosphomolybdic acid were obtained from Acros Organics (Geel, Belgium). Iron(III) chloride was purchased from Riedel-de-Haën (Seelze, Germany). Folin-Ciocalteau's phenol reagent, potassium hexacyanoferrate(III), and sodium nitroprusside were purchased from Merck (Darmstadt, Germany). Methanol, phosphoric acid, and toluene were provided by T.T.T. (Zagreb, Croatia). Butanol, hydrochloric acid, and methanol (HPLC grade) were obtained from Lach-Ner (Neratovice, Czech Republic). Ethyl acetate, sulphuric acid, and hydrochloric acid were purchased from POCH S.A. (Gliwice, Poland).

\subsection{Plant Material and Extract Preparation}

The leaves of seven selected Salvia species were collected during the flowering period between May and August 2018 from different locations in Croatia as follows: S. fruticosa Mill. (Vis, $43^{\circ} 03^{\prime} 01.3^{\prime \prime} \mathrm{N}, 16^{\circ} 04^{\prime} 14.5^{\prime \prime} \mathrm{E}$ ), S. glutinosa L. (Čabar, $45^{\circ} 27^{\prime} 42.6^{\prime \prime} \mathrm{N}, 14^{\circ} 49^{\prime} 36.4^{\prime \prime}$ E), S. nemorosa L. (Baranja, 45 $49^{\prime} 34.1^{\prime \prime} \mathrm{N}, 18^{\circ} 45^{\prime} 29.3^{\prime \prime}$ E), S. officinalis L. (Dugi otok, $\left.44^{\circ} 04^{\prime} 47.0^{\prime \prime} \mathrm{N}, 14^{\circ} 59^{\prime} 40.7^{\prime \prime} \mathrm{E}\right)$, S. pratensis L. (Zagreb, $\left.45^{\circ} 47^{\prime} 04.6^{\prime \prime} \mathrm{N}, 15^{\circ} 59^{\prime} 51.3^{\prime \prime} \mathrm{E}\right)$, S. sclarea L. (Dugi otok, $44^{\circ} 04^{\prime} 47.0^{\prime \prime} \mathrm{N}, 14^{\circ} 59^{\prime} 40.7^{\prime \prime} \mathrm{E}$ ), and S. verticillata L. (Ogulin, $45^{\circ} 18^{\prime} 32.7^{\prime \prime} \mathrm{N}$, $15^{\circ} 16^{\prime} 44.5^{\prime \prime}$ E). The plant species were authenticated by the Department of Botany, Faculty of Science and the Department of Pharmacognosy, Faculty of Pharmacy and Biochemistry (University of Zagreb, Croatia), where the voucher specimens were deposited under the genus number 817. In order to investigate the biological activities of selected Salvia species, air-dried plant material was pulverized into a fine powder and used for extract preparation. Afterward, $50 \mathrm{~mL}$ of $70 \%$ ethanol was added to $5.0 \mathrm{~g}$ of pulverized plant material and the extraction procedure was carried out in an ultrasonic bath (Bandelin Sonorex digital 10P, Germany) for $30 \mathrm{~min}$ at $30^{\circ} \mathrm{C}$. After filtration, the sample was reextracted after which a new portion of $50 \mathrm{~mL}$ of $70 \%$ ethanol was added to the plant residue. The newly obtained extract was filtered after the extraction procedure was repeated in the above-mentioned conditions. The filtrates were combined and concentrated to dryness with a rotary evaporator (Büchi Rotavapor, Switzerland). The extraction yields for S. fruticosa, S. glutinosa, S. nemorosa, S. officinalis, S. pratensis, S. sclarea, and S. verticillata were 26.17, 18.00, 23.56, 34.17, 30.80, 22.19, and $34.39 \%$, respectively. Additionally, Salvia ethanolic extracts were analysed for thujone presence by thin-layer chromatography according to method A described in the European Pharmacopoeia [24], as well as method B by Wagner and Bladt [25]. The mobile phase containing ethyl acetate and toluene in proportions 5:95 v/v (A) or 7:93 $v / v(B)$ was used. Aliquots of $0.1 \% \alpha / \beta$-thujone $(20 \mu \mathrm{L})$ and $1 \%$ Salvia extracts $(10 \mu \mathrm{L})$ were manually applied on a silica gel HPTLC plate (Merck, Germany). The plate was sprayed with a solution of phosphomolybdic acid in 96\% ethanol (A) or anisaldehyde-sulphuric acid reagent (B) and heated at $100-105^{\circ} \mathrm{C}$ for $10 \mathrm{~min}$. Neither Salvia chromatograms examined in daylight showed any pale blue (A) or violet zones (B) matching $R_{f}$ value as that of thujone in the reference solution.

\subsection{Total Flavonoids Determination}

The total flavonoid contents in the leaves of selected Salvia species were determined spectrophotometrically according to the method described in the European Pharmacopoeia [24]. Firstly, $0.600 \mathrm{~g}$ of pulverized plant material was extracted with $1.0 \mathrm{~mL}$ of hexamethylenetetramine $(5 \mathrm{~g} / \mathrm{L}), 20 \mathrm{~mL}$ of acetone, and $2.0 \mathrm{~mL}$ of hydrochloric acid $(250 \mathrm{~g} / \mathrm{L})$ in a water bath under reflux for $30 \mathrm{~min}$. The mixture was cooled and filtered through cotton and the 
residue was extracted twice with $20 \mathrm{~mL}$ of acetone for $10 \mathrm{~min}$. The filtrates were combined and diluted with acetone to $100.0 \mathrm{~mL}$. Afterward, $20.0 \mathrm{~mL}$ of the obtained acetone extract was mixed with $20 \mathrm{~mL}$ of distilled water and extracted once with $15 \mathrm{~mL}$ and three times with $10 \mathrm{~mL}$ of ethyl acetate. The ethyl acetate fractions were combined and washed twice with $50 \mathrm{~mL}$ of distilled water, filtered through anhydrous sodium sulphate, and diluted with ethyl acetate to $50.0 \mathrm{~mL}$. Afterward, $10.0 \mathrm{~mL}$ of the ethyl acetate extract was mixed with $1.0 \mathrm{~mL}$ of an aluminium chloride solution and diluted with a 5\% methanolic solution of acetic acid to $25.0 \mathrm{~mL}$. The absorbance of the test solution was measured after $30 \mathrm{~min}$ at $425 \mathrm{~nm}$, after which the percentage of total flavonoids, expressed as isoquercitrin, was calculated according to the following equation: $(\%)=A \times 1.25 / \mathrm{m}$. $A$ represents the absorbance of the test solution whereas $m$ represents the mass of used plant material in grams.

\subsection{Total Phenolic Acids Determination}

The total phenolic acid contents in the leaves of selected Salvia species were determined spectrophotometrically according to the European Pharmacopoeia [24]. Firstly, $0.200 \mathrm{~g}$ of pulverised leaves were extracted with $50 \%$ ethanol in a water bath under reflux. After cooling and filtration, the extract was diluted to $100.0 \mathrm{~mL}$ with $50 \%$ ethanol. Afterward, $1.0 \mathrm{~mL}$ of the extract was mixed with $2.0 \mathrm{~mL}$ of $0.5 \mathrm{M}$ hydrochloric acid, $2.0 \mathrm{~mL}$ water solution of sodium nitrate and sodium molybdate, as well as $2.0 \mathrm{~mL}$ of $8.5 \%$ sodium hydroxide and diluted using distilled water to $10.0 \mathrm{~mL}$. The absorbance of the test solution was measured immediately at $505 \mathrm{~nm}$ and the percentage of total phenolic acids, expressed as rosmarinic acid, was calculated according to the following expression: $(\%)=A \times 2.5 / \mathrm{m}$. $A$ stands for the absorbance of the test solution while $m$ stands for the mass of tested plant material in grams.

\subsection{Total Tannins Determination}

The total tannin contents in the leaves of selected Salvia species were determined spectrophotometrically using the assay described in the European Pharmacopoeia [24]. Firstly, $1.000 \mathrm{~g}$ of pulverized leaves were extracted with distilled water in a water bath under reflux. After cooling, the water extract was filtered, transferred into a volumetric flask, diluted to $250.0 \mathrm{~mL}$, and filtered. After discarding the first $50 \mathrm{~mL}, 10.0 \mathrm{~mL}$ of the filtrate was mechanically stirred with the addition of hide powder for $60 \mathrm{~min}$, filtrated, and diluted with water to $25.0 \mathrm{~mL}$, after which $2.0 \mathrm{~mL}$ of said solution was mixed with $1.0 \mathrm{~mL}$ of the Folin-Ciocalteau's reagent, as well as $10.0 \mathrm{~mL}$ of water. The mixture was diluted to $25.0 \mathrm{~mL}$ with sodium carbonate $(290 \mathrm{~g} / \mathrm{L})$ and the absorbance was measured after a 30-min incubation at $760 \mathrm{~nm}$. The content of total tannins, expressed as pyrogallol, was calculated according to the following expression: $(\%)=62.5 \times\left(A_{1}-A_{2}\right) \times m_{2} / A_{3} \times m_{1} . A_{1}$ stands for the absorbance of the test solution, which was not pre-treated with hide powder; $A_{2}$ represents the absorbance of the test solution treated with hide powder; $A_{3}$ stands for the absorbance of the standard pyrogallol; $m_{1}$ represents the mass of tested plant material in grams, and $m_{2}$ stands for the mass of pyrogallol.

\subsection{Total Anthocyanins Determination}

The total anthocyanin contents in the leaves of selected Salvia species were determined spectrophotometrically following the assay described in the European Pharmacopoeia [24]. Firstly, $5.00 \mathrm{~g}$ of pulverized leaves were mixed with methanol and mechanically stirred for $30 \mathrm{~min}$. The methanolic extract was filtered and diluted to $100.0 \mathrm{~mL}$ with methanol. The solution was once again diluted 50 times with a $0.1 \%$ methanolic solution of hydrochloric acid. The absorbance was measured immediately at $528 \mathrm{~nm}$. The content of total anthocyanins, expressed as cyanidine-3-glucoside chloride, was calculated using the following equation: $(\%)=A \times 5000 / 718 \times m$. $A$ represents the absorbance of the test solution whereas $m$ represents the mass of tested plant material in grams. 


\subsection{Determination of Phenolic Acids and Flavonoids by High-Performance Liquid Chromatography}

The contents of phenolic acids in the leaves of selected Salvia species were determined by the high-performance liquid chromatography method described in the European Pharmacopoeia [24]. The analysis was performed using the Agilent 1100 HPLC system with Zorbax RRHD Eclipse plus C18 column $(4.6 \times 250 \mathrm{~mm}, 5 \mu \mathrm{m})$. Firstly, pulverised leaf material $(0.100 \mathrm{~g})$ was extracted for $30 \mathrm{~min}$ with $90 \mathrm{~mL}$ of $50 \%$ ethanol in a water bath under reflux. The extract was cooled and filtered into a volumetric flask, diluted to $100.0 \mathrm{~mL}$ with $50 \%$ ethanol, then additionally filtered through a $0.45 \mu \mathrm{m}$ syringe filter. The reference solutions of the phenolic acids were prepared by dissolving $20.0 \mathrm{mg}$ of each in $50 \%$ ethanol and diluted to $100.0 \mathrm{~mL}$. The solution was diluted fivefold and filtered through a $0.45 \mu \mathrm{m}$ filter. Mobile phase A consisted of phosphoric acid, acetonitrile, and water (1:19:80 v/v/v), while mobile phase $B$ contained phosphoric acid, methanol, and acetonitrile (1:40:59 v/v/v). Eluents were used in the following gradient program: 0-20 min $(0-45 \% \mathrm{~B}), 20-25 \mathrm{~min}$ $(45-100 \% \mathrm{~B})$, and $25-30 \mathrm{~min}(100-0 \% \mathrm{~B})$. The flow rate was adjusted to $1.2 \mathrm{~mL} / \mathrm{min}$. Phenolic acid detection was conducted at $330 \mathrm{~nm}$. The amounts of rosmarinic, chlorogenic, $p$-coumaric, caffeic, and ferulic acids were calculated by using the peak area normalisation procedure and the results were expressed as $\mu \mathrm{g}$ of active substance per $\mathrm{g}$ of herbal material.

The quantification of apigenin, apigenin-7-O-glucoside, luteolin, luteolin-7-O-glucoside, quercetin, and rutin in the Salvia extracts was carried out according to the method previously described by Bljajić et al. [26]. The analysis was performed using the Agilent HPLC system (Agilent 1200 series, Agilent Technologies, Santa Clara, CA, USA) with the Eclipse XDB-C18 column $(4.6 \times 250 \mathrm{~mm}, 5 \mu \mathrm{m})$ and guard column, equipped with an autosampler as well as a DAD detector. Firstly, $1.0 \mathrm{~g}$ of corresponding herbal material was extracted for $15 \mathrm{~min}$ with $10 \mathrm{~mL}$ of $96 \%$ ethanol in a water bath under reflux. The extract was cooled and then filtered through a $0.45 \mu \mathrm{m}$ syringe filter. The phenolic standards $(0.1-0.2 \mathrm{mg} / \mathrm{mL})$ were also filtered and subjected to HPLC chromatographic separation. Mobile phase A (water, methanol, and formic acid in proportions 93:5:2 v/v/v) and mobile phase B (water, methanol, and formic acid in proportions 3:95:2 $\mathrm{v} / \mathrm{v} / \mathrm{v}$ ) were utilized in the following order: $0 \mathrm{~min} 20 \% \mathrm{~B}, 10 \mathrm{~min} 40 \% \mathrm{~B}$, and $35 \mathrm{~min} 50 \% \mathrm{~B}$. The separation was performed at $40{ }^{\circ} \mathrm{C}$ and at the flow of $1.0 \mathrm{~mL} / \mathrm{min}$. All flavonoids were detected and quantified at $270 \mathrm{~nm}$ using corresponding calibration curves. The peak assignment and identification were based on the comparison of UV/VIS spectra and retention times of the peaks in the sample chromatograms with those of the standards. The results were expressed as $\mu \mathrm{g}$ of active substance per $g$ of herbal material.

\subsection{DPPH Radical Scavenging Activity}

The DPPH radical scavenging activity of the ethanolic extracts of selected Salvia species was determined according to the method described by Vladimir-Knežević et al. [27]. Briefly, the solutions of plant extracts and the reference standards in different concentrations $(0.78-50 \mu \mathrm{g} / \mathrm{mL})$ were prepared in ethanol, respectively. Afterward, a $0.1 \mathrm{mM}$ solution of DPPH was prepared in ethanol as well, and $0.5 \mathrm{~mL}$ of said reagent was then added to $1.5 \mathrm{~mL}$ of test solutions. After being vigorously shaken, the samples were kept in the dark for $30 \mathrm{~min}$. Their absorbance was measured afterward at $517 \mathrm{~nm}$ against an appropriate blank. The DPPH radical scavenging capability was calculated according to the following equation: $(\%)=\left[\left(A_{0}-A_{1}\right) / A_{0}\right] \times 100 . A_{0}$ represents the absorbance of the control solution whereas $A_{1}$ represents the absorbance of the test solution.

\subsection{NO Radical Scavenging Activity}

The NO radical scavenging activity of selected Salvia species was tested according to the method used by Patel et al. [28] with slight modifications. Ethanolic plant extracts and the reference standards were prepared in different concentrations $(6.25-400 \mu \mathrm{g} / \mathrm{mL})$. Afterward, $1.0 \mathrm{~mL}$ of freshly prepared $10 \mathrm{mM}$ solution of sodium nitroprusside in phosphatebuffered saline $(\mathrm{pH}=7.4)$ was added to $1 \mathrm{~mL}$ of test solutions. The test tube contents were shaken vigorously and incubated at room temperature for two hours. Afterward, $0.5 \mathrm{~mL}$ 
of tested samples were transferred in a new set of test tubes and mixed with $1.0 \mathrm{~mL}$ of $1 \%$ solution of sulphanilamide in $5 \%$ phosphoric acid. After a 5-min incubation at room temperature, $1.0 \mathrm{~mL}$ of $0.1 \%$ solution of $\mathrm{N}$-(1-naphthyl)ethylenediamine dihydrochloride was added to the samples and their absorbance was measured immediately after shaking at $540 \mathrm{~nm}$ with the use of an appropriate blank. NO radical scavenging activity was calculated with the following equation: $(\%)=\left[\left(A_{0}-A_{1}\right) / A_{0}\right] \times 100$, where $A_{0}$ is the absorbance of the control solution and $A_{1}$ is the absorbance of the test solution.

\subsection{Reducing Power Assay}

The reducing power of seven Salvia species was determined according to the assay described by Vladimir-Knežević et al. [27]. A series of ethanolic extract solutions and reference standards were prepared in different concentrations (1.56-100 $\mu \mathrm{g} / \mathrm{mL})$. After the addition of $2.5 \mathrm{~mL}$ of $0.2 \mathrm{M}$ phosphate buffer $(\mathrm{pH}=6.6)$ and $2.5 \mathrm{~mL}$ of $1 \%$ solution of potassium hexacyanoferrate(III), the samples were incubated for $20 \mathrm{~min}$ at $50{ }^{\circ} \mathrm{C}$. Then, $2.5 \mathrm{~mL}$ of $10 \%$ solution of trichloroacetic acid was added to the test solutions. Afterwards, $2.5 \mathrm{~mL}$ of the supernatant was mixed with $2.5 \mathrm{~mL}$ of distilled water and $0.5 \mathrm{~mL}$ of $0.1 \%$ solution of iron(III) chloride, and the absorbance of tested samples was measured at $700 \mathrm{~nm}$ against a blank.

\subsection{Iron Chelating Activity}

The iron-chelating activity of Salvia species in comparison with EDTA as the reference chelator was determined according to the slightly modified method conducted by Benabdallah et al. [29]. Firstly, ethanolic solutions of plant extracts and a water solution of EDTA were prepared in different concentrations $(100-1600 \mu \mathrm{g} / \mathrm{mL}$ and $0.78-12.5 \mu \mathrm{g} / \mathrm{mL}$, respectively). After adding $0.3 \mathrm{~mL}$ of $0.1 \mathrm{mM}$ solution of iron (II) sulphate heptahydrate to $0.3 \mathrm{~mL}$ of test solutions, the mixture was incubated for $10 \mathrm{~min}$ at room temperature. After the addition of $0.3 \mathrm{~mL}$ of $0.25 \mathrm{mM}$ solution of ferrozine in the next step, the vigorously shaken samples were once again incubated at room temperature for the same amount of time and their absorbance was promptly measured at $562 \mathrm{~nm}$ with the use of a blank. The percentage of iron-chelating ability was calculated according to the following equation: $(\%)=\left[\left(A_{0}-A_{1}\right) / A_{0}\right] \times 100 . A_{0}$ represents the absorbance of the control solution while $A_{1}$ represents the absorbance of the test solution.

\subsection{Lipid Peroxidation Inhibition Assay}

The lipid peroxidation inhibition assay for seven selected Salvia species was carried out according to the method described by Houghton et al. [30]. Ethanolic plant extracts and rosmarinic acid as the reference standard were prepared in dimethyl sulfoxide in different concentrations (50-400 $\mu \mathrm{g} / \mathrm{mL}$ and $12.5-100 \mu \mathrm{g} / \mathrm{mL}$, respectively). Afterward, $10 \mu \mathrm{L}$ of each test solution was mixed with $0.5 \mathrm{~mL}$ of the bovine brain extract suspension in phosphatebuffered saline $(5 \mathrm{mg} / \mathrm{mL}, \mathrm{pH}=7.4)$. After the addition of $0.1 \mathrm{~mL}$ of $1 \mathrm{mM}$ solution of iron(III) chloride, $0.29 \mathrm{~mL}$ of $10 \mathrm{mM}$ phosphate-buffered saline, and $0.1 \mathrm{~mL}$ of $1 \mathrm{mM}$ solution of ascorbic acid, respectively, the test solutions were incubated for $60 \mathrm{~min}$ at $37^{\circ} \mathrm{C}$. After incubation, $1 \mathrm{~mL}$ of $1 \%$ solution of thiobarbituric acid in $0.05 \mathrm{M}$ sodium hydroxide, $1 \mathrm{~mL}$ of $2.8 \%$ solution of trichloroacetic acid, and $0.1 \mathrm{~mL}$ of $2 \%$ solution of BHT were added into the mixture. The test solutions were then heated in a boiling water bath for $20 \mathrm{~min}$. After cooling, $2 \mathrm{~mL}$ of butanol was added to the mixture after which $1 \mathrm{~mL}$ of the samples' supernatant was transferred into new test tubes. The absorbance of tested samples was measured at $532 \mathrm{~nm}$ against an appropriate blank and the percentage of lipid peroxidation inhibition was calculated by using the following equation: $(\%)=\left[\left(A_{0}-A_{1}\right) / A_{0}\right] \times 100$. $A_{0}$ stands for the absorbance of the control solution while $A_{1}$ stands for the absorbance of the test solution. 


\subsection{Acetylcholinesterase Inhibition Assay}

The acetylcholinesterase inhibition assay for tested Salvia species was conducted according to the method developed by Conforti et al. [31]. Solutions of plant extracts, rosmarinic acid, and galantamine were prepared in dimethyl sulfoxide in different concentrations (100-1600 $\mu \mathrm{g} / \mathrm{mL})$. Afterward, $20 \mu \mathrm{L}$ of each test solution was mixed with $40 \mu \mathrm{L}$ of an acetylcholinesterase solution $(0.02 \mathrm{U} / \mathrm{mL})$ and $1.9 \mathrm{~mL}$ of $50 \mathrm{mM}$ Tris- $\mathrm{HCl}$ buffer $(\mathrm{pH}=8)$, after which the samples were kept at $4{ }^{\circ} \mathrm{C}$ for $30 \mathrm{~min}$. After incubation, $40 \mu \mathrm{L}$ of a mixture of $10 \mathrm{mM}$ solution of 5,5'-dithiobis-2-nitrobenzoic acid and $12 \mathrm{mM}$ solution of acetylthiocholine iodide was added to the samples and their absorbance was measured promptly after stirring and once again after ten minutes at $412 \mathrm{~nm}$. The percentage of acetylcholinesterase inhibition was obtained according to the following equation: $(\%)=\left[\left(A_{0}-A_{1}\right) / A_{0}\right] \times 100 . A_{0}$ stands for the difference in the absorbance of the control solution measured immediately and ten minutes later, whereas $A_{1}$ stands for the difference in the absorbance of the test solution measured immediately and ten minutes later.

\subsection{4. $\alpha$-Glucosidase Inhibition Assay}

The $\alpha$-glucosidase inhibition assay for tested Salvia species was carried out according to the method described by Bljajić et al. [32] with slight modifications. Solutions of the plant extracts $(100 \mu \mathrm{L})$ were prepared in $10 \%$ dimethyl sulfoxide in different concentrations (400-6400 $\mu \mathrm{g} / \mathrm{mL})$. Afterward, the solutions were mixed with $50 \mu \mathrm{L}$ of the $\alpha$-glucosidase solution $(1.0 \mathrm{U} / \mathrm{mL})$, which was prepared in $0.1 \mathrm{M}$ phosphate buffer $(\mathrm{pH}=6.8)$, and incubated for $10 \mathrm{~min}$ at $37^{\circ} \mathrm{C}$. After incubation, $50 \mu \mathrm{L}$ of the substrate 4-nitrophenyl$\alpha$-glucopyranoside $(1.25 \mathrm{mM})$ prepared in the same buffer was added to the mixture. Absorbance was measured at $405 \mathrm{~nm}$ after a 5-min incubation at room temperature against a blank which contained the equivalent volume of phosphate buffer instead of the substrate. The antidiabetic drug acarbose was used as the positive control during the experiment while a solution containing $10 \%$ dimethyl sulfoxide instead of plant extracts were used as the negative control. The enzyme inhibitory activity was calculated according to the following equation: $(\%)=\left[\left(A_{0}-A_{1}\right) / A_{0}\right] \times 100 . A_{0}$ stands for the absorbance of the control solution which contains $10 \%$ dimethyl sulfoxide instead of tested samples, whereas $A_{1}$ represents the absorbance of the solution which contains either Salvia extracts or acarbose.

\subsection{Statistical Analysis}

All the above-mentioned experiments were carried out in triplicates and the results are expressed as mean \pm standard deviation. The $\mathrm{IC}_{50}$ values were calculated by linear regression extrapolation. The differences between the obtained results were determined by the ordinary one-way ANOVA and post hoc Tukey's multiple comparisons test. Pearson's correlation coefficient was calculated to find the degree of association between the two variables. All statistical analyses were accomplished by the GraphPad Prism software (version 8.4.3) as well as Microsoft Excel. All values with $p<0.05$ were considered statistically significant.

\section{Results and Discussion}

\subsection{Phytochemical Analysis of Polyphenolic Compounds in Selected Salvia Species}

Along with other species of the mint family, the sage plants are being recognized as a promising source of polyphenols that exhibit a remarkable diversity of both chemical structures and biological activities $[2,8,33]$. The contents of different groups of polyphenolic components, phenolic acids, flavonoids, tannins, and anthocyanins, in the leaves of selected Salvia species, were determined spectrophotometrically and obtained results are presented in Table 1. The most abundant compounds for all the investigated species were phenolic acids (3.55-12.44\%), followed by tannins (1.22-2.60\%), and flavonoids (0.31-1.07\%). As expected, the percentage of anthocyanins was very low $(0.02-0.08 \%)$. The leaves of $S$. verticillata contained the highest amount of phenolic acids $(12.44 \%)$ while the lowest concentration was determined in S. sclarea (3.55\%). The contents of phenolic acids in the other 
sage plants were from $6.48 \%$ to $8.04 \%$. Among studied Salvia species, S. glutinosa was found to contain the largest amount of tannins $(2.60 \%)$, flavonoids $(1.07 \%)$, and anthocyanins $(0.08 \%)$. In addition to $S$. glutinosa, S. nemorosa, S. pratensis, and S. sclarea were also rich in flavonoids $(0.75-0.90 \%)$.

Table 1. Content of total flavonoids, phenolic acids, tannins, and anthocyanins (\%) in the leaves of selected Salvia species.

\begin{tabular}{|c|c|c|c|c|}
\hline Sample & Flavonoids & Phenolic Acids & Tannins & Anthocyanins \\
\hline S. fruticosa & $0.31 \pm 0.009 \mathrm{~g}$ & $7.05 \pm 0.13^{c}$ & $1.80 \pm 0.08^{b}$ & $0.02 \pm 0.001^{\mathrm{f}}$ \\
\hline S. glutinosa & $1.07 \pm 0.002^{\mathrm{a}}$ & $6.95 \pm 0.22^{c}$ & $2.60 \pm 0.08^{a}$ & $0.08 \pm 0^{\mathrm{a}}$ \\
\hline S. nemorosa & $0.88 \pm 0.004^{c}$ & $6.48 \pm 0.01^{\mathrm{d}}$ & $1.40 \pm 0.12^{c}$ & $0.06 \pm 0.002^{b}$ \\
\hline S. officinalis & $0.37 \pm 0.002^{f}$ & $8.04 \pm 0.10^{b}$ & $1.83 \pm 0.04^{b}$ & $0.03 \pm 0.002^{\mathrm{e}}$ \\
\hline S. pratensis & $0.90 \pm 0.007^{b}$ & $6.49 \pm 0.01^{d}$ & $1.37 \pm 0.13^{c}$ & $0.05 \pm 0.002^{c}$ \\
\hline S. sclarea & $0.75 \pm 0.002^{\mathrm{d}}$ & $3.55 \pm 0.04^{\mathrm{e}}$ & $1.22 \pm 0.04^{\mathrm{c}}$ & $0.05 \pm 0^{\mathrm{c}}$ \\
\hline S. verticillata & $0.39 \pm 0.003^{\mathrm{e}}$ & $12.44 \pm 0.01^{\mathrm{a}}$ & $1.67 \pm 0.09^{b}$ & $0.04 \pm 0.002^{\mathrm{d}}$ \\
\hline
\end{tabular}

The data are expressed as mean values of three independent experiments \pm standard deviation. Mean values displaying different letters within each column are significantly different according to Tukey's multiple comparisons test at a $95 \%$ confidence level.

Previous research on Salvia species frequently involved the spectrophotometric determination of total phenols, phenolic acids, and/or flavonoids in some of the tested sage plants with the aim to correlate their contents and bioactivity. Zupkó et al. [34] determined the total phenol and flavonoid contents in several Salvia species, including S. glutinosa, S. nemorosa, S. officinalis, S. pratensis, and S. verticillata. Except for S. glutinosa $(2.5 \%), 50 \%$ of methanolic extracts contained less than $1 \%$ of flavonoids. On the other hand, the proportion of total phenols among tested Salvia extracts varied considerably (1-26\%). Previous reports also indicate a great variability in the total phenolics (expressed as gallic acid equivalents) of Salvia extracts of various polarity as follows: S. officinalis (2-293 mg/g) [35-38], S. fruticosa (24-267 mg/g) [39-43], S. nemorosa (40-295 mg/g) [44-46], S. sclarea (30-268 mg/g) [41,42,44,47,48], and S. verticillata $(50-176 \mathrm{mg} / \mathrm{g})[46,47,49]$. Contrary to the above, the total phenolics in different samples of $S$. glutinosa were quite similar $(38-43 \mathrm{mg} / \mathrm{g})[44,50]$. Apart from $S$. fruticosa which contained flavonoids in a wide range from 4 to $346 \mathrm{mg}$ rutin/g $[43,51]$, the variability in the total flavonoids and phenolic acids within and between Salvia species was significantly less than that of total phenols. The content of total flavonoids in S. glutinosa was $16 \mathrm{mg}$ rutin/g [50], while $2 \mathrm{mg}$ rutin/g was determined in both S. sclarea and S. verticillata $[47,49]$. Furthermore, $S$. nemorosa, $S$. sclarea, and $S$. verticillata were found to contain 29,26 , and 39-42 mg/g of total phenolic acids expressed as caffeic acid equivalents, respectively [47]. Due to the differences in the type of extract and plant parts used, determination method, or expression of the results, it is difficult to accurately compare previous findings with each other and with our results. However, in accordance with previous research, our study clearly revealed that all investigated Salvia extracts can be considered as rich sources of polyphenols. Furthermore, we confirmed that our Salvia ethanolic extracts do not contain $\alpha / \beta$-thujone, which contributes to the safety aspects of their potential application.

Since phenolic acids were found to be the major class of phenolic compounds for all studied Salvia species, the contents of selected phenolic acids were additionally determined by the HPLC-DAD method. Rosmarinic, chlorogenic, $p$-coumaric, caffeic, and ferulic acids were quantified due to their frequent occurrence in sage plants [39,49,52]. According to the results presented in Table 2, rosmarinic acid was the most abundant in the leaves of all investigated plants, which is consistent with previously reported data $[35,39,53]$. The contents of rosmarinic acid were ranging from $9400 \mu \mathrm{g} / \mathrm{g}$ (S. glutinosa) to 38,800 $\mu \mathrm{g} / \mathrm{g}$ (S. officinalis). The highest percentage of chlorogenic and $p$-coumaric acid was also found in the leaves of S. officinalis (2100 and 11,600 $\mathrm{g} / \mathrm{g}$, respectively). S. fruticosa and S. verticillata contained a significant amount of rosmarinic acid (29,100 and 30,200 $\mu \mathrm{g} / \mathrm{g}$, respectively) and were the richest in caffeic acids. Moreover, ferulic acid was detected only in the leaves 
of those two species. When comparing our findings with the previous phytochemical studies, both similarities and differences can be observed. The highest concentration of rosmarinic acid in Salvia officinalis was also reported by Farhat et al. [35]; however, our study highlighted the Croatian specimen as a much richer source than the Tunisian one $(13,680-18,378 \mu \mathrm{g} / \mathrm{g})$. Alongside this, the concentrations of rosmarinic acid in S. officinalis and S. fruticosa reported by Cvetkovikj et al. [53] were $25.98 \mathrm{mg} / \mathrm{g}$ and $10.72 \mathrm{mg} / \mathrm{g}$, respectively, which is significantly lower compared to our results. According to Šlniūte et al. [54], who studied ten Salvia spp. growing in Lithuania, the major phenolic acids were rosmarinic and caffeic acids. Their contents in the ethanolic extracts of S. glutinosa (9225 and $630 \mu \mathrm{g} / \mathrm{g}$, respectively) and S. officinalis (30,017 and $605 \mu \mathrm{g} / \mathrm{g}$, respectively) were in line with our results, despite a different extraction method. However, $S$. verticillata and $S$. pratensis analysed in our study contained the two- and threefold higher amounts of rosmarinic acid, respectively. Comparable to our findings, Katanić Stanković et al. [49] also reported higher rosmarinic acid content in Serbian $S$. verticillata.

Table 2. Content of phenolic acids and flavonoids ( $\mu \mathrm{g} / \mathrm{g}$ of herbal material) of selected Salvia species determined by the HPLC-DAD method.

\begin{tabular}{|c|c|c|c|c|c|c|c|}
\hline Compound & S. fruticosa & S. glutinosa & S. nemorosa & S. officinalis & S. pratensis & S. sclarea & S. verticillata \\
\hline \multicolumn{8}{|c|}{ Phenolic acids } \\
\hline Caffeic acid & $1300 \pm 10^{b}$ & $300 \pm 0^{\mathrm{f}}$ & $300 \pm 10^{\mathrm{f}}$ & $400 \pm 10^{\mathrm{e}}$ & $600 \pm 10^{c}$ & $500 \pm 20^{d}$ & $4100 \pm 40^{\mathrm{a}}$ \\
\hline $\begin{array}{l}\text { Chlorogenic } \\
\text { acid }\end{array}$ & $300 \pm 10^{\mathrm{f}}$ & $300 \pm 10^{\mathrm{f}}$ & $1900 \pm 10^{b}$ & $2100 \pm 30^{a}$ & $1600 \pm 10^{c}$ & $1200 \pm 40^{\mathrm{e}}$ & $1500 \pm 30^{\mathrm{d}}$ \\
\hline$p$-Coumaric & $9000 \pm 130^{b}$ & $1200 \pm 10^{\mathrm{e}}$ & $1600 \pm 20^{\mathrm{e}}$ & $11,600 \pm 500^{a}$ & $600 \pm 10^{f}$ & $2900 \pm 20^{d}$ & $8400 \pm 120^{c}$ \\
\hline Ferulic acid & $1400 \pm 20^{b}$ & n.d. & n.d. & n.d. & n.d. & n.d. & $2200 \pm 30^{\mathrm{a}}$ \\
\hline $\begin{array}{l}\text { Rosmarinic } \\
\text { acid }\end{array}$ & $29,100 \pm 210^{c}$ & $9400 \pm 70^{g}$ & $14,200 \pm 110^{f}$ & $38,800 \pm 270^{a}$ & $19,500 \pm 120^{d}$ & $17,900 \pm 130^{\mathrm{e}}$ & $30,200 \pm 210^{b}$ \\
\hline \multicolumn{8}{|c|}{ Flavonoids } \\
\hline $\begin{array}{l}\text { Apigenin-7- } \\
\text { O-glc }\end{array}$ & n.d. & $156.83 \pm 0.21$ & n.d. & $\begin{array}{l}13.48 \pm 0.11 \\
\text { n.d. }\end{array}$ & n.d. & $\begin{array}{c}83.68 \pm 0.25 \\
\text { n.d. }\end{array}$ & $\begin{array}{l}\text { n.a. } \\
\text { n.d. }\end{array}$ \\
\hline Luteolin & $11.86 \pm 0.03^{\mathrm{e}}$ & n.d. & n.d. & $27.51 \pm 0.14^{c}$ & $25.62 \pm 0.09^{\mathrm{d}}$ & $163.54 \pm 0.19^{a}$ & $31.48 \pm 0.14^{\mathrm{b}}$ \\
\hline $\begin{array}{l}\text { Luteolin-7- } \\
\text { O-glc }\end{array}$ & $306.81 \pm 0.14^{\mathrm{a}}$ & $51.73 \pm 0.12^{c}$ & n.d. & $55.74 \pm 0.21^{b}$ & n.d. & n.d. & n.d. \\
\hline $\begin{array}{l}\text { Quercetin } \\
\text { Rutin }\end{array}$ & $\begin{array}{c}21.77 \pm 0.10^{b} \\
\text { n.d. }\end{array}$ & $\begin{array}{l}\text { n.d. } \\
\text { n.d. }\end{array}$ & $\begin{array}{l}\text { n.d. } \\
\text { n.d. }\end{array}$ & $\begin{array}{c}\text { n.d. } \\
75.28 \pm 0.10^{\mathrm{b}}\end{array}$ & $\begin{array}{c}\text { n.d. } \\
76.24 \pm 0.11^{\text {a }}\end{array}$ & $\begin{array}{l}\text { n.d. } \\
\text { n.d. }\end{array}$ & $\begin{array}{c}59.02 \pm 0.18^{\mathrm{a}} \\
\text { n.d. }\end{array}$ \\
\hline
\end{tabular}

The data are expressed as mean values of three independent experiments \pm standard deviation. Mean values displaying different letters within each row are significantly different according to Tukey's multiple comparisons test at a 95\% confidence level. n.d.: not detected.

As can be seen in Table 2, apigenin, luteolin, and their glycosidic derivatives were detected in the studied Salvia extracts, along with quercetin and rutin, which are all typical flavonoids present in sage plants $[49,51,53]$. However, the amounts of analysed flavonoids in tested samples were much lower than that of phenolic acids. The most common flavonoids found were luteolin and luteolin-7-O-glucoside. Their concentrations in Salvia leaves ranged from $11.86 \mu \mathrm{g} / \mathrm{g}$ (S. fruticosa) to $163.54 \mu \mathrm{g} / \mathrm{g}$ (S. sclarea) and from $51.73 \mu \mathrm{g} / \mathrm{g}$ (S. glutinosa) to $306.81 \mu \mathrm{g} / \mathrm{g}$ (S. fruticosa), respectively. Apigenin-7-O-glucoside was identified only in S. glutinosa $(156.83 \mu \mathrm{g} / \mathrm{g})$, although its aglycone apigenin was quantified in S. sclarea, S. officinalis, and S. fruticosa. Similarly, the extracts of S. fruticosa and S. verticillata contained quercetin, while its glycosidic derivative was detected only in S. officinalis and S. pratensis. Our study shows that S. officinalis, besides rutin, contains apigenin, luteolin, and their glucosides, but their concentrations were remarkably lower in comparison to a previous report [35]. Sarrou et al. [51] reported that the phenolic content and composition of $S$. fruticosa is greatly influenced by the harvest period, and found, contrary to our results, that luteolin is more present as the free aglycone. According to our findings, none of the monitored flavonoids have been detected in S. nemorosa, which is not in line with the previous papers $[45,47]$ that reported quercetin and rutin. However, our results on the presence of luteolin and apigenin in S. sclarea support previous findings [47,52]. Hanganu et al. [47] quantified luteolin, apigenin, and rutin in the ethanolic extracts of $S$. 
verticillata, but did not detect quercetin, which indicates the great variations in the flavonoid composition of this sage species.

\subsection{Antioxidant Activities of Selected Salvia Species}

Various mechanisms of action can be simultaneously involved in the antioxidant effects of complex plant extracts, such as free radical scavenging, termination of oxidative chain reactions, reducing capacity, and binding of prooxidant metal ions [55,56]. Therefore, in our study, five different assays were employed to evaluate the antioxidant properties of the ethanolic extracts of selected Salvia species as well as to elucidate their mode of action. The most used antioxidant method, the DPPH assay, allowed us to determine the ability of plant extracts to act as free radical scavengers. DPPH is a stable free organic radical which can be neutralized in the presence of an antioxidant, via electron or hydrogen atom transfer, resulting in a colour change that can be easily monitored spectrophotometrically. All tested Salvia extracts demonstrated a concentration-dependent free radical scavenging ability (Supplementary Materials Table S1). To compare the antioxidant properties of these sage plants, the concentrations of extracts required to reduce the initial radical concentration by $50 \%\left(\mathrm{IC}_{50}\right)$ were determined, and the results are given in Figure 1 . A lower $\mathrm{IC}_{50}$ value indicates a higher ability of the sample to act as an antioxidant. All tested Salvia species showed a high potency of free radical scavenging. According to the determined $\mathrm{IC}_{50}$ values $(2.49-7.71 \mu \mathrm{g} / \mathrm{mL})$, the antioxidant efficiency order was $S$. verticillata $>$ S. fruticosa $>$ S. officinalis $>$ S. nemorosa $>$ S. glutinosa $>$ S. pratensis $>$ S. sclarea. DPPH scavenging activity was the focus of previous antioxidant studies of sage plants [35,39,40,44,47,49,57-59]. Although all studies revealed the antiradical potential of Salvia species, large variations in testing conditions, type of extracts, and reported results were found. Our study pointed out that $S$. verticillata ethanolic extract demonstrated the strongest antioxidative properties equal to Trolox $\left(\mathrm{IC}_{50}=2.50 \mu \mathrm{g} / \mathrm{mL}\right)$. However, Hanganu et al. [47] reported significantly higher concentrations of the $S$. verticillata ethanolic extract required for a $50 \%$ inhibition $(42.92 \mu \mathrm{g} / \mathrm{mL})$. S. nemorosa, S. pratensis, and S. sclarea also demonstrated much stronger scavenging activity than that reported in the above-mentioned study. In addition, our results on the DPPH scavenging activity of S. glutinosa and S. officinalis ethanolic extracts were comparable to earlier reports on $\mathrm{IC}_{50}$ values of methanolic extracts $(3.2 \mu \mathrm{g} / \mathrm{mL}$ and $3.37 \mu \mathrm{g} / \mathrm{mL}$, respectively) [35,44]. On the contrary, Brindisi et al. [60] reported much higher concentrations of $S$. officinalis methanolic extract required to scavenge $50 \%$ of the initial DPPH radicals (10.3-12.4 $\mu \mathrm{g} / \mathrm{mL}$ ). Tzanova et al. [61] indicated significantly lower antiradical activity of S. sclarea in comparison to $S$. verticillata, which is in accordance with our findings. Katanić Stanković et al. [49] reported that $S$. verticillata methanolic extract achieved an $\mathrm{IC}_{50}$ value of $33.04 \mu \mathrm{g} / \mathrm{mL}$, while our study demonstrated tenfold stronger antioxidant activity of the Croatian specimen. Overall, our results reveal that the Salvia extracts can scavenge free radicals due to their hydrogen atom- and/or the electron-donating ability and, therefore, may be able to suppress initiation and/or propagation of free radical-mediated chain reactions. Considering that polyphenols are the main compounds with antioxidant properties in plant extracts, the Pearson correlation coefficient $(r)$ was calculated to assess the relationship between the content of polyphenols and the antioxidant effect of the studied sage plants (Supplementary Materials Table S8). The correlation analysis revealed a very strong correlation between free radical scavenging activity and total phenolic acid content in Salvia species $(r=0.9478)$. Our data also suggest that caffeic, ferulic, and rosmarinic acid also contribute significantly to the antiradical activity of the sage plants. These results agree with the previous report [47]. A strong positive correlation between the quercetin content and DPPH scavenging activity $(r=0.8958)$ was also observed. 
DPPH· scavenging activity

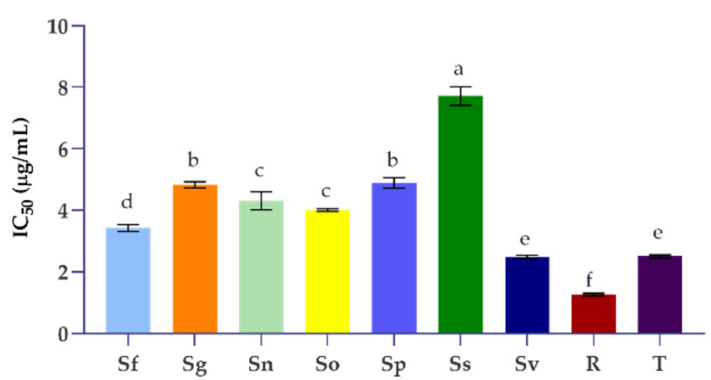

(a)

Reducing power

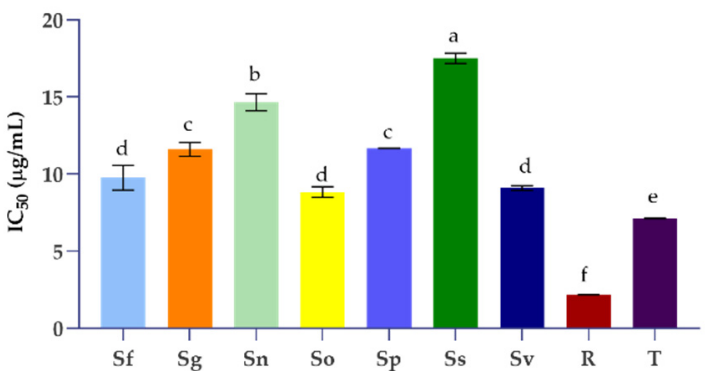

(c)

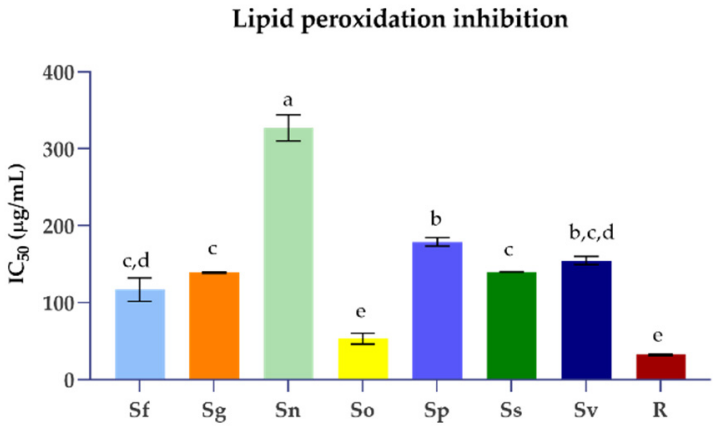

NO- scavenging activity

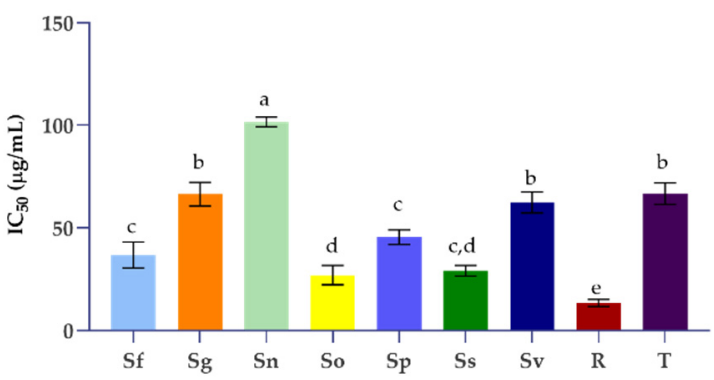

(b)

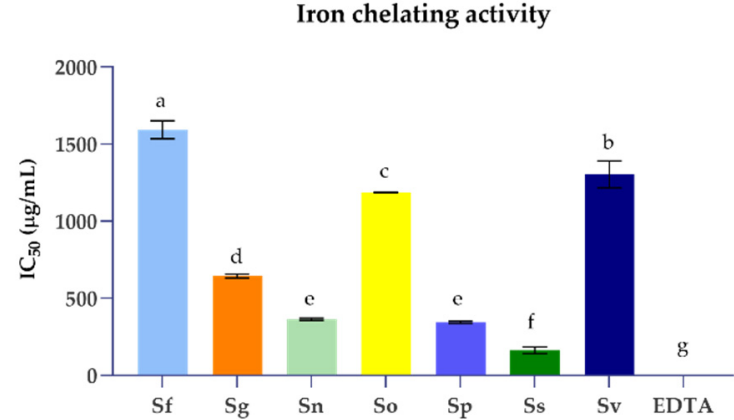

(d)

(e)

Figure 1. Comparative overview of antioxidant effects $\left(\mathrm{IC}_{50}\right.$ values) of the ethanolic extracts of S. fruticosa (Sf), S. glutinosa (Sg), S. nemorosa (Sn), S. officinalis (So), S. pratensis (Sp), S. sclarea (Ss), and $S$. verticillata $(\mathrm{Sv})$, as well as rosmarinic acid (R), trolox (T), and EDTA obtained for (a) DPPH scavenging activity, (b) NO scavenging activity, (c) reducing power, (d) iron chelating activity, (e) lipid peroxidation inhibition. The data are expressed as mean values of three independent experiments \pm standard deviation and different small letters indicate a statistically significant difference (Tukey's multiple comparisons test at 95\% confidence level).

Nitric oxide (NO) is a biologically relevant free radical which, when produced in excessive amounts, reacts with another free radical, the superoxide anion, and forms highly reactive nitrogen species. Therefore, testing the ability of natural compounds to directly scavenge NO is suggested as a promising pharmacological strategy for the prevention and treatment of pathological conditions associated with oxidative stress, such as inflammatory and neurodegenerative disorders [55]. All tested Salvia species demonstrated NO scavenging activity in a concentration-dependent manner (Supplementary Materials Table S2). At the concentration of $100 \mu \mathrm{g} / \mathrm{mL}$, the extracts of all investigated Salvia species were capable of scavenging more than $55 \%$ of generated NO radicals. However, the selected Salvia species displayed a wide range of $\mathrm{IC}_{50}$ values, from $26.96 \mu \mathrm{g} / \mathrm{mL}$ to $101.73 \mu \mathrm{g} / \mathrm{mL}$ (Figure 1 ). The 
S. officinalis ethanolic extract exhibited the most effective NO radical scavenging ability, followed by the extracts of S. sclarea, S. fruticosa, and S. pratensis $(29.10-45.49 \mu \mathrm{g} / \mathrm{mL})$. Interestingly, the mentioned Salvia extracts demonstrated significantly stronger antioxidative properties than Trolox $\left(\mathrm{IC}_{50}=66.69 \mu \mathrm{g} / \mathrm{mL}\right.$ ). In addition, equal effects to those of Trolox were observed for S. verticillata and S. glutinosa, which also indicated their exceptional antioxidant properties. Rosmarinic acid was found to be a very potent NO scavenger $(13.44 \mu \mathrm{g} / \mathrm{mL})$. According to our results (Supplementary Materials Table S8), there is a moderate correlation between the NO scavenging activity of tested extracts and rosmarinic acid content $(r=0.5789)$, as well as $p$-coumaric acid $(r=0.5127)$, apigenin $(r=0.6242)$ and luteolin $(r=0.5762)$ contents. As far as our literature survey could ascertain, the data presented here are the first record on the NO scavenging ability for most of the investigated Salvia species. Only one recent study on the antioxidant activity of S. verticillata reported that the methanolic extract of aerial parts possesses $\mathrm{NO}$ radical scavenging activity $\left(\mathrm{IC}_{50}=73.12 \mu \mathrm{g} / \mathrm{mL}\right)$, corresponding to our results [49].

The antioxidant properties of Salvia species in comparison with rosmarinic acid and Trolox were also evaluated by reducing the power assay. Antioxidants have an electrondonating ability and can cause the reduction of the $\mathrm{Fe}^{3+} /$ ferricyanide complex to the ferrous form. The $\mathrm{IC}_{50}$ value provided absorbance of 0.5 and was calculated from the graph of absorbance against sample concentration [27]. All tested Salvia extracts were active in a concentration-dependent manner (Supplementary Materials Table S3). The absorbance values between 0.405 and 0.681 were determined for all samples at the concentration of $12.5 \mu \mathrm{g} / \mathrm{mL}$. S. officinalis, S. verticillata, and S. fruticosa, containing the highest amounts of total phenolic acids, as well as rosmarinic acid (2.91-3.88\%), were the most active sage plants. These findings can be correlated to the lowest IC 50 values from 8.83 to $9.75 \mu \mathrm{g} / \mathrm{mL}$. The rest of the tested Salvia species achieved $\mathrm{IC}_{50}$ values from $11.60 \mu \mathrm{g} / \mathrm{mL}$ to $17.51 \mu \mathrm{g} / \mathrm{mL}$ (Figure 1). Rosmarinic acid acted as a strong electron donor, demonstrating activity that was four times higher than the Salvia extracts with the best reducing power. The obtained results indicate a great contribution of rosmarinic and other phenolic acids to the reducing power capability of tested sage extracts. These observations were confirmed by Pearson's coefficient (Supplementary Materials Table S8) which showed a strong correlation of reducing power and total phenolic acid content $(r=0.7784)$, as well as rosmarinic acid content $(r=0.7735)$. Our findings are in accordance with previous studies suggesting that the ability of different extracts of S. fruticosa, S. officinalis, S. sclarea, and S. verticillata to reduce $\mathrm{Fe}^{3+}$ are strongly correlated with caffeic acid derivatives contents $[41,47,59]$. On the other hand, the reported results for Libyan S. fruticosa indicate no correlation between caffeic acid content and reducing power [40]. Inconsistent findings could be attributed to the use of various plant samples, extraction solvents, and testing methods.

The antioxidant properties of plant polyphenols are attributed to their ability to chelate transition metal ions which are known to catalyse an initial formation of reactive oxygen species [27]. In that context, the ability of selected Salvia species to chelate transition metal ions was tested by an iron-chelating activity assay with ferrozine as a competitive $\mathrm{Fe}^{2+}$ chelator. The ethanolic extracts of the Salvia species were tested in the concentration range from 100 to $1600 \mu \mathrm{g} / \mathrm{mL}$, in comparison with EDTA as a reference chelating agent. All extracts achieved the efficiency of 52.57-83.99\% at the highest tested concentration (Supplementary Materials Table S4). S. sclarea with an $\mathrm{IC}_{50}$ value of $163.02 \mu \mathrm{g} / \mathrm{mL}$ demonstrated the strongest chelating activity, while the highest $\mathrm{IC}_{50}$ values (1185.54-1582.53 $\mu \mathrm{g} / \mathrm{mL}$ ) were determined for S. officinalis, S. verticillata, and S. fruticosa (Figure 1). In contrast to $S$. sclarea, those three species, although rich in rosmarinic and total phenolic acids, showed weak chelating properties. A correlation between chelating ability and rosmarinic acid content as well as total phenolic acid content was not found (Supplementary Materials Table S8). Moreover, in this assay, rosmarinic acid demonstrated no activity at all, additionally indicating that the effectiveness of the tested Salvia extract could be attributed to flavonoids $(r=0.4752)$, individually apigenin $(r=0.8073)$, and luteolin $(r=0.8228)$. Our results confirm previous studies that showed weak chelating activities 
of S. glutinosa, S. officinalis, and S. verticillata $[26,49,62]$. On the contrary, one recent study demonstrated no chelating ability of $S$. sclarea even at the concentration of $2000 \mu \mathrm{g} / \mathrm{mL}$ [63].

Lipid peroxidation is a process in which oxidants attack lipids, especially polyunsaturated fatty acids. Under high lipid peroxidation rates, oxidative damage can overwhelm the cell repair capacity and cause various pathological conditions. One of the major toxic components generated by lipid peroxidation is malondialdehyde which can be spectrophotometrically detected by adding thiobarbituric acid [64]. The lipid peroxidation inhibition assay was conducted for selected Salvia species in comparison with rosmarinic acid. All tested ethanolic extracts inhibited lipid peroxidation in a concentration-dependent manner (Supplementary Materials Table S5). The ethanolic extract of S. officinalis was the most potent one $\left(\mathrm{IC}_{50}=53.18 \mu \mathrm{g} / \mathrm{mL}\right)$ followed by S. fruticosa, S. glutinosa, S. sclarea, S. verticillata, S. pratensis, and S. nemorosa, with $\mathrm{IC}_{50}$ values from $116.83 \mu \mathrm{g} / \mathrm{mL}$ to $327.23 \mu \mathrm{g} / \mathrm{mL}$ (Figure 1). Obtained results accentuated rosmarinic acid as a potent inhibitor of lipid peroxidation and additionally confirmed its status as a significant antioxidant. A strong correlation $(r=0.7426)$ between rosmarinic acid content and inhibition of lipid peroxidation was confirmed. In addition, the content of rutin moderately correlated with the lipid peroxidation inhibitory activity $(r=0.5505)$ (Supplementary Materials Table S8). Our findings are consistent with previous investigations of $S$. officinalis from Algeria, whose ethanolic extract showed similar inhibition of lipid peroxidation [36]. In addition, the aqueous extract of S. officinalis 'Icterina' also demonstrated a strong inhibitory property [65]. The methanolic extract of S. verticillata from Serbia was found to be more potent than the ethanolic extract of $S$. verticillata tested in our study [49]. Moreover, in contrast to our results, the study performed by Zupkó et al. [34] reported much lower $\mathrm{IC}_{50}$ values for methanolic leaf extracts of S. glutinosa, S. nemorosa, S. officinalis, and S. pratensis, probably due to the differences in experimental procedures.

\subsection{Acetylcholinesterase and $\alpha$-Glucosidase Inhibitory Activities of Selected Salvia Species}

Alzheimer's disease (AD) is an irreversible neurodegenerative disorder characterised by a lack of neurotransmitter acetylcholine which has a key role in cognitive functions. Currently, the most prescribed drugs for AD treatment are cholinesterase inhibitors. In traditional European medicine, Salvia species are recognised for their memory-enhancing abilities $[45,62,66]$; so, within our study, we evaluated the acetylcholinesterase (AChE) inhibitory activity of selected Salvia species. Among tested Salvia species, only three of them were found to possess a certain capability to inhibit AChE (Table 3, Supplementary Materials Table S6). At the concentration of $400 \mu \mathrm{g} / \mathrm{mL}$, S. fruticosa and S. officinalis inhibited $80 \%$ of the AChE enzyme activity. There was no statistical difference between their IC $_{50}$ values (287.02 and $268.45 \mu \mathrm{g} / \mathrm{mL}$, respectively) which were slightly higher than that of rosmarinic acid. S. verticillata achieved its $\mathrm{IC}_{50}$ value almost at the highest tested concentration of $1600 \mu \mathrm{g} / \mathrm{mL}$. S. glutinosa, S. nemorosa, S. sclarea, and S. pratensis did not reach a 50\% efficacy in the tested concentration range. Observed enzyme inhibitory activities strongly correlated with the presence of rosmarinic acid $(r=0.8168), p$-coumaric acid $(r=0.8727)$, and luteolin-7-Oglucoside $(r=0.7050)$ in Salvia ethanolic extracts (Supplementary Materials Table S8). Our findings are consistent with other reports that also highlighted a significant contribution of rosmarinic acid to the neuroprotective properties of S. officinalis [50]. Bahadori et al. [45] reported that $S$. nemorosa methanolic, dichloromethane and hexane extracts showed $50 \%$ inhibitory activities in the range of $223.4-469.9 \mu \mathrm{g} / \mathrm{mL}$ which was not confirmed by our research. A previous report by Demirezer et al. $[63,66]$ indicated significantly better AChE inhibitory activity of $S$. fruticosa in comparison to $S$. verticillata that we demonstrated in our study. Furthermore, literature data also reveal a low or non-existent AChE inhibitory potential of S. sclarea, S. glutinosa, and S. verticillata [63,67]. 
Table 3. Antiacetylcholinesterase and anti- $\alpha$-glucosidase activities $\left(\mathrm{IC}_{50}\right.$ values, $\left.\mu \mathrm{g} / \mathrm{mL}\right)$ of the ethanolic extracts of selected Salvia species, rosmarinic acid, and reference compounds.

\begin{tabular}{ccc}
\hline Sample & Acetylcholinesterase Inhibition & $\alpha$-Glucosidase Inhibition \\
\hline S. fruticosa & $287.02 \pm 6.94^{\mathrm{b}}$ & $5291.51 \pm 335.08^{\mathrm{a}}$ \\
S. glutinosa & n.d. & $4496.06 \pm 66.36^{\mathrm{b}}$ \\
S. nemorosa & n.d. & n.d. \\
S. officinalis & $268.45 \pm 14.14^{\mathrm{b}}$ & $4451.85 \pm 142.22^{\mathrm{b}}$ \\
S. pratensis & n.d. & n.d. \\
S. sclarea & n.d & n.d. \\
S. verticillata & $1607.87 \pm 15.05^{\mathrm{a}}$ & n.d. \\
rosmarinic acid & $234.77 \pm 14.77^{\mathrm{c}}$ & $4927.45 \pm 324.81^{\mathrm{b}}$ \\
galantamine & $0.12 \pm 0.01^{\mathrm{d}}$ & - \\
acarbose & - & $1104.76 \pm 34.80^{\mathrm{c}}$
\end{tabular}

The data are expressed as mean values of three independent experiments \pm standard deviation. Mean values displaying different letters within each column are significantly different according to Tukey's multiple comparisons test at a 95\% confidence level. n.d.: not determined, -: not tested.

Diabetes is a complex progressive metabolic disorder that occurs due to insulin secretion deficiencies associated with high blood glucose levels. Chronic hyperglycemia is associated with long-term damage and dysfunction of many organs. Previous studies suggested that certain plant extracts may have beneficial effects on diabetes. Moreover, the history of some antidiabetic drugs such as metformin is linked to the traditional use of medicinal plants [2,67]. The strategy of reducing carbohydrate digestibility by controlling the activity of hydrolyzing enzymes of the small intestine is considered a viable prophylactic treatment of hyperglycemia. Acarbose is classified as an $\alpha$-glucosidase inhibitor and is often used as a positive control in antidiabetic research. Synthetic antidiabetic drugs are usually associated with gastrointestinal side effects. Therefore, numerous studies have been conducted to identify enzyme inhibitors from natural sources. Various Salvia species have shown the great potential to be explored as an alternative strategy in diabetic therapies $[67,68]$. In view of all of the above, we evaluated the $\alpha$-glucosidase inhibitory activity of selected Salvia species. Although all sage extracts in the tested concentrations $(400-6400 \mu \mathrm{g} / \mathrm{mL}$ ) showed the ability to inhibit the enzyme (Supplementary Materials Table S7), IC 50 values were detected only for S. fruticosa, S. officinalis, and S. glutinosa. ranging from $4451 \mu \mathrm{g} / \mathrm{mL}$ to $5291 \mu \mathrm{g} / \mathrm{mL}$. As it can be seen from Table 3, these values were four to five times higher than the $\mathrm{IC}_{50}$ value determined for acarbose. S. officinalis and S. fruticosa were the most potent enzyme inhibitors and their effects did not differ statistically from that of rosmarinic acid. Mocan et al. [50] also found that these two species equally inhibited $\alpha$-glucosidase. Mahdi et al. [37] revealed that the ethyl acetate fraction of $S$. officinalis hydro-methanol decoction extract had the best antidiabetic activity tested both by $\alpha$-amylase and $\alpha$-glucosidase assays, which corresponded to the highest content of phenolic compounds. In this study, we show that tannins contributed the most to the observed enzyme inhibition activity of Salvia extracts which was indicated by the high correlation coefficient $(r=0.7934)$. A moderate correlation was also observed between the content of luteolin-7-O-glucoside and the $\alpha$-glucosidase inhibitory activity in tested sage plants $(r=0.5791)$ (Supplementary Materials Table S8). Contrary to our results, one study reported that $S$. nemorosa methanolic extract had an $\alpha$-glucosidase inhibitory effect comparable to acarbose [45]. Considering the above, our findings contributed to the elucidation of the antidiabetic potential of selected Salvia species by demonstrating their ability to inhibit $\alpha$-glucosidase involved in carbohydrate digestion.

Recent evidence suggests that Alzheimer's disease is closely related to impaired cerebral glucose metabolism and insulin resistance, as seen in type 2 diabetes. Insulin plays an important neuroprotective and trophic role in brain cells by preventing apoptosis, $\beta$ amyloid toxicity, and oxidative stress, as well as promoting neuronal survival and memory. Diabetes and neurodegenerative diseases have been found to share some insulin resistancerelated mechanisms with oxidative stress as a pathogenic background $[69,70]$. In this 
context, our findings reveal that polyphenol-rich Salvia ethanolic extracts have the potential to prevent and mitigate neurodegenerative changes in diabetes by reducing oxidative stress and inhibiting enzymes involved in glucose metabolism and acetylcholine loss.

\section{Conclusions}

This study provides evidence of the antioxidant ability, AChE, and $\alpha$-glucosidase inhibitory activities of wild-growing Salvia species from the Mediterranean region. To our knowledge, this is the first comparative study of selected Salvia species in terms of the biological activities tested. Moreover, some data on certain species were reported for the first time. All tested plants were able to scavenge free radicals, act as reducing agents, chelate transition metals, and inhibit lipid peroxidation as well as AChE and $\alpha$-glucosidase. Together with S. fruticosa and S. officinalis, S. verticillata, and S. glutinosa, respectively, were the most effective antioxidants as well as AChE and $\alpha$-glucosidase inhibitors. The observed biological activities of Salvia species were positively influenced mainly by total phenolic acids, total tannins, and rosmarinic acid, which was identified as the most abundant one (9400-38,800 $\mu \mathrm{g} / \mathrm{g})$. Other phenolic acids, such as caffeic, chlorogenic, $p$-coumaric, and ferulic acid, were also predominant in sage leaves $(300-11,600 \mu \mathrm{g} / \mathrm{g})$, in contrast to flavonoids, which were significantly less represented $(10.82-306.81 \mu \mathrm{g} / \mathrm{g})$. Luteolin, apigenin, quercetin, and their glycosidic derivatives were identified in the sage extracts; however, their content and composition varied significantly between tested specimens. Overall, our results reveal Salvia ethanolic extracts as a valuable source of polyphenols which are potent antioxidants with a multitarget mechanism of action, as well as moderate AChE and $\alpha$-glucosidase inhibitors. Therefore, they can be considered as promising therapeutic agents for oxidative stress-related chronic diseases, such as diabetes, cardiovascular and neurodegenerative diseases, and serve as nutraceuticals and food preservatives.

Supplementary Materials: The following supporting information can be downloaded at: https: / / www.mdpi.com/article/10.3390/plants11050625/s1, Table S1: DPPH radical scavenging activity (\%) of selected Salvia species in comparison with rosmarinic acid and a reference antioxidant; Table S2: NO free radical scavenging activity (\%) of selected Salvia species in comparison with rosmarinic acid and a reference antioxidant; Table S3: Reducing power of selected Salvia species in comparison with rosmarinic acid and a reference antioxidant; Table S4: Iron(II) ions chelating activity (\%) of selected Salvia species in comparison with rosmarinic acid and a reference chelator; Table S5: Inhibition of lipid peroxidation (\%) of selected Salvia species in comparison with rosmarinic acid; Table S6: Inhibition of acetylcholinesterase (\%) of selected Salvia species in comparison with rosmarinic acid and galantamine; Table S7: Inhibition of $\alpha$-glucosidase (\%) determined in the ethanolic extracts of selected Salvia species in comparison with acarbose, Table S8: The Pearson's correlation coefficients between biological activities and polyphenolic contents of selected Salvia species.

Author Contributions: Conceptualization, S.V.-K.; methodology, S.V.-K., M.B.Š., M.K., B.B.; formal analysis, M.M. (Mateja Mervić), B.B., M.M. (Marijan Marijan); investigation, M.M. (Mateja Mervić), M.K., M.B.Š., M.M. (Marijan Marijan); writing—original draft preparation, M.M. (Mateja Mervić), M.B.Š., M.K., B.B.; writing-review and editing, S.V.-K.; visualization, M.M. (Mateja Mervić); supervision, S.V.-K. All authors have read and agreed to the published version of the manuscript.

Funding: This research was funded by the project "Bioactive molecules of medical plants as natural antioxidants, microbicides, and preservatives" (KK.01.1.1.04.0093), co-financed by the Croatian Government and the European Union through the European Regional Development Fund-Operational Programme Competitiveness and Cohesion (KK.01.1.1.04).

Institutional Review Board Statement: Not applicable.

Informed Consent Statement: Not applicable.

Data Availability Statement: All data that support the findings of this study are available in the Supplementary Materials of this article. 
Conflicts of Interest: The authors declare no conflict of interest. The funders had no role in the design of the study; in the collection, analyses, or interpretation of data; in the writing of the manuscript, or in the decision to publish the results.

\section{References}

1. Walker, J.B.; Sytsma, K.J. Staminal evolution in the genus Salvia (Lamiaceae): Molecular phylogenetic evidence for multiple origins of the staminal lever. Ann. Bot. 2007, 100, 375-391. [CrossRef]

2. Rashed, A.A.; Gunasegavan Rathi, D.N. Bioactive components of Salvia and their potential antidiabetic properties: A review. Molecules 2021, 26, 3042. [CrossRef]

3. Askari, S.F.; Avan, R.; Tayarani-Najaran, Z.; Sahebkar, A.; Eghbali, S. Iranian Salvia species: A phytochemical and pharmacological update. Phytochemistry 2021, 183, 112619. [CrossRef]

4. Tulukcu, E.; Cebi, N.; Sagdic, O. Chemical fingerprinting of seeds of seeds of some Salvia species in Turkey by using GC-MS and FTIR. Foods 2019, 8, 118. [CrossRef]

5. Lopresti, A.L. Salvia (Sage): A review of its potential cognitive-enhancing and protective effects. Drugs $R D$ 2017, 17, 53-64 [CrossRef]

6. Lu, Y.; Foo, L.Y. Polyphenolics of Salvia-A review. Phytochemistry 2002, 59, 117-140. [CrossRef]

7. Bonesi, M.; Loizzo, M.R.; Acquaviva, R.; Malfa, G.A.; Aiello, F.; Tundis, R. Anti-inflammatory and antioxidant agents from Salvia genus (Lamiaceae): An assessment of the current state of knowledge. Antiinflamm. Antiallergy Agents Med. Chem. 2017, 16, 70-86. [CrossRef]

8. Afonso, A.F.; Pereira, O.R.; Cardoso, S.M. Salvia species as nutraceuticals: Focus on antioxidant, antidiabetic and anti-obesity properties. Appl. Sci. 2021, 11, 9365. [CrossRef]

9. Ververis, A.; Savvidou, G.; Ioannou, K.; Nicolaou, P.; Christodoulou, K.; Plioukas, M. Greek sage exhibits neuroprotective activity against amyloid beta-induced toxicity. Evid. Based Complement. Altern. Med. 2020, 2020, 2975284. [CrossRef]

10. Hao, D.C.; Ge, G.B.; Xiao, P.G. Anticancer drug targets of Salvia phytometabolites: Chemistry, biology and omics. Curr. Drug Targets 2018, 19, 1-20. [CrossRef]

11. Flora Croatica Database. Available online: https://hirc.botanic.hr/fcd/ (accessed on 15 October 2021).

12. Craft, J.D.; Satyal, P.; Setzer, W.N. The chemotaxonomy of common sage (Salvia officinalis) based on the volatile constituents. Medicines 2017, 4, 47. [CrossRef]

13. Tursun, A.O.; Sipahioglu, H.M.; Telci, I. Genetic relationships and diversity within cultivated accessions of Salvia officinalis L. in Turkey. Plant Biotechnol. Rep. 2021, 15, 663-672. [CrossRef]

14. European Medicines Agency. Available online: https://www.ema.europa.eu (accessed on 1 October 2021).

15. KammounEl Euch, S.; Hassine, D.B.; Cazaux, S.; Bouzouita, N.; Bouajila, J. Salvia officinalis essential oil: Chemical analysis and evaluation of anti-enzymatic and antioxidant bioactivities. S. Afr. J. Bot. 2017, 120, 253-260. [CrossRef]

16. Ghorbani, A.; Esmaeilizadeh, M. Pharmacological properties of Salvia officinalis and its components. J. Tradit. Complement. Med. 2017, 7, 433-440. [CrossRef]

17. Sabry, M.M.; Abdel-Rahman, R.; El-Shenawy, S.M.; Hassan, A.M.; El-Gayed, S.H. Estrogenic activity of Sage (Salvia officinalis L.) aerial parts and its isolated ferulic acid in immature ovariectomized female rats. J. Ethnopharmacol. 2022, 282, 114579. [CrossRef]

18. Tundis, R.; Leporini, M.; Bonesi, M.; Rovito, S.; Passalacqua, N.G. Salvia officinalis L. from Italy: Comparative chemical and biological study of its essential oil in the Mediterranean context. Molecules 2020, 25, 5826. [CrossRef]

19. Montesino, N.L.; Kaiser, M.; Mäser, P.; Schmidt, T.J. Salvia officinalis L.: Antitrypanosomal activity and active constituents against Trypanosoma brucei rhodesiense. Molecules 2021, 26, 3226. [CrossRef]

20. Sarikhan, H.; Tavan, M.; Rigano, M.M.; Azizi, A. Triterpenic and phenolic acids production changed in Salvia officinalis via in vitro and in vivo polyploidization: A consequence of altered genes expression. Phytochemistry 2021, 189, 112803.

21. Martins, N.; Barros, L.; Santos-Buelga, C.; Silva, S.; Ferreira, I.C.F.R. Evaluation of bioactive properties and phenolic compounds in different extracts prepared from Salvia officinalis L. Food Chem. 2015, 170, 378-385. [CrossRef]

22. Dent, M.; Bursač-Kovačević, D.; Bosiljkov, T.; Dragović-Uzelac, V. Polyphenolic composition and antioxidant capacity of indigenous wild dalmatian sage (Salvia officinalis L). Croat. Chem. Acta 2017, 90, 451-459. [CrossRef]

23. Velamuri, R.; Sharma, Y.; Fagan, J.; Schaefer, J. Application of UHPLC-ESI-QTOF-MS in phytochemical profiling of sage (Salvia officinalis) and rosemary (Rosmarinus officinalis). Planta Med. Int. Open 2020, 7, 133-144. [CrossRef]

24. European Pharmacopoeia Online. Available online: https://pheur.edqm.eu/home (accessed on 19 April 2021)

25. Wagner, H.; Bladt, S. Plant Drug Analysis, 2nd ed.; Springer: Berlin, Germany, 2009; pp. 90-91.

26. Bljajić, K.; Brajković, A.; Čačić, A.; Vujić, L.; Jablan, J.; de Carvalho, I.S.; Zovko Končić, M. Chemical composition, antioxidant and $\alpha$-glucosidase-inhibitory activity of aqueous and hydroethanolic extracts of traditional antidiabetics from Croatian ethnomedicine. Horticulturae 2021, 7, 15. [CrossRef]

27. Vladimir-Knežević, S.; Blažeković, B.; Bival Štefan, M.; Alegro, A.; Köszegi, T.; Petrik, J. Antioxidant activities and polyphenolic contents of three selected Micromeria species from Croatia. Molecules 2011, 16, 1454-1470. [CrossRef] [PubMed]

28. Patel, A.; Patel, A.; Patel, A.; Patel, N.M. Determination of polyphenols and free radical scavenging activity of Tephrosia purpurea Linn leaves (Leguminosae). Pharmacogn. Res. 2010, 2, 152-158. [CrossRef] 
29. Benabdallah, A.; Rahmoune, C.; Boumendjel, M.; Aissi, O.; Messaoud, C. Total phenolic content and antioxidant activity of six wild Mentha species (Lamiaceae) from northeast of Algeria. Asian Pac. J. Trop. Biomed. 2016, 6, 760-766. [CrossRef]

30. Houghton, P.J.; Zarka, R.; de las Heras, B.; Hoult, J.R. Fixed oil of Nigella sativa and derived thymoquinone inhibit eicosanoid generation in leukocytes and membrane lipid peroxidation. Planta Med. 1995, 61, 33-36. [CrossRef]

31. Conforti, F.; Statti, G.A.; Tundis, R.; Loizzo, M.R.; Menichini, F. In vitro Activities of Citrus medica L. cv. Diamante (Diamante citron) relevant to treatment of diabetes and Alzheimer's disease. Phytother. Res. 2007, 21, 427-433. [CrossRef]

32. Bljajić, K.; Petlevski, R.; Vujić, L.; Čačić, A.; Šoštarić, N.; Jablan, J.; Saraiva de Carvalho, I.; Zovko Končić, M. Chemical composition, antioxidant and $\alpha$-glucosidase inhibiting activities of the aqueous and hydroethanolic extracts of Vaccinium myrtillus leaves. Molecules 2017, 22, 703. [CrossRef]

33. Vladimir-Knežević, S.; Blažeković, B.; Kindl, M.; Vladić, J.; Lower-Nedza, A.D.; Brantner, A.H. Acetylcholinesterase inhibitory, antioxidant and phytochemical properties of selected medicinal plants of the Lamiaceae family. Molecules 2014, 19, 767-782. [CrossRef]

34. Zupkó, I.; Hohmann, J.; Rédei, D.; Falkay, G.; Janicsák, G.; Máthé, I. Antioxidant activity of leaves of Salvia species in enzymedependent and enzyme-independent systems of lipid peroxidation and their phenolic constituents. Planta Med. 2001, 67, 366-368. [CrossRef]

35. Farhat, M.B.; Landoulsi, A.; Chaouch-Hamada, R.; Sotomayor, J.A.; Jordán, M.J. Characterization and quantification of phenolic compounds and antioxidant properties of Salvia species growing in different habitats. Ind. Crops Prod. 2013, 49, 904-914. [CrossRef]

36. Boufadi, A.M.Y.; Keddari, S.; Moulai-Hacene, F.; Chaa, S. Chemical composition, antioxidant and anti-inflammatory properties of Salvia officinalis extract from Algeria. Pharmacogn. J. 2021, 13, 506-515. [CrossRef]

37. Mahdi, S.; Rachid, A.; Lahfa, B.F. Evaluation of in vitro $\alpha$-amylase and $\alpha$-glucosidase inhibitory potential and hemolytic effect of phenolic enriched fractions of the aerial part of Salvia officinalis L. Diabetes Metab. Syndr. Clin. Res. Rev. 2020, 14, 689-694. [CrossRef] [PubMed]

38. Jeshvaghani, Z.A.; Rahimmalek, M.; Talebi, M.; Goli, S.A.H. Comparison of total phenolic content and antioxidant activity in different Salvia species using three model systems. Ind. Crops Prod. 2015, 77, 409-414. [CrossRef]

39. Dincer, C.; Topuz, A.; Sahin-Nadeem, H.; Ozdemir, K.S.; Cam, I.B.; Tontul, I.; Gokturk, R.S.; Ay, S.T. A comparative study on phenolic composition, antioxidant activity and essential oil content of wild and cultivated sage (Salvia fruticosa Miller) as influenced by storage. Ind. Crops Prod. 2012, 39, 170-176. [CrossRef]

40. Duletić-Laušević, S.; Alimpić Aradski, A.; Šavikin, K.; Knežević, A.; Milutinović, M.; Stević, T.; Vukojević, J.; Marković, S.; Marin, P.D. Composition and biological activities of Libyan Salvia fruticosa Mill. and S. lanigera Poir. extracts. S. Afr. J. Bot. 2018, 117, 101-109. [CrossRef]

41. Vergine, M.; Nicolì, F.; Negro, C.; Luvisi, A.; Nutricati, E.; Annunziata Accogli, R.; Sabella, E.; Miceli, A. Phytochemical profiles and antioxidant activity of Salvia species from southern Italy. Rec. Nat. Prod. 2019, 13, 205-215. [CrossRef]

42. Stagos, D.; Portesis, N.; Spanou, C.; Mossialos, D.; Aligiannis, N.; Chaita, E.; Panagoulis, C.; Reri, E.; Skaltsounis, L.A.; Tsatsakis, A.M.; et al. Correlation of total polyphenolic content with antioxidant and antibacterial activity of 24 extracts from Greek domestic Lamiaceae species. Food Chem. Toxicol. 2012, 50, 4115-4124. [CrossRef]

43. Şenol, F.S.; Orhan, I.E.; Celep, F.; Kahraman, A.; Doğan, M.; Yılmaz, G.; Şener, B. Survey of 55 Turkish Salvia taxa for their acetylcholinesterase inhibitory and antioxidant activities. Food Chem. 2010, 120, 34-43. [CrossRef]

44. Loizzo, M.R.; Abouali, M.; Salehi, P.; Sonboli, A.; Kanani, M.; Menichini, F.; Tundis, R. In vitro antioxidant and antiproliferative activities of nine Salvia species. Nat. Prod. Res. 2014, 28, 2278-2285. [CrossRef]

45. Bahadori, M.B.; Asghari, B.; Dinparast, L.; Zengin, G.; Sarikurkcu, C.; Abbas-Mohammadi, M.; Bahadori, S. Salvia nemorosa L.: A novel source of bioactive agents with functional connections. LWT-Food Sci. Technol. 2017, 75, 42-50. [CrossRef]

46. Tosun, M.; Ercisli, S.; Sengul, M.; Ozer, H.; Polat, T.; Ozturk, E. Antioxidant properties and total phenolic content of eight Salvia species from Turkey. Biol. Res. 2009, 42, 175-181. [CrossRef] [PubMed]

47. Hanganu, D.; Olah, N.K.; Pop, C.E.; Vlase, L.; Oniga, I.; Ciocarlan, N.; Matei, A.; Puşcaş, C.; Silaghi-Dumitrescu, R.; Benedec, D. Evaluation of the polyphenolic profile and antioxidant activity for some Salvia species. Farmacia 2019, 67, 801-805. [CrossRef]

48. Asadi, S.; Ahmadiani, A.; Esmaeili, M.A.; Sonboli, A.; Ansari, N.; Khodagholi, F. In vitro antioxidant activities and an investigation of neuroprotection by six Salvia species from Iran: A comparative study. Food Chem. Toxicol. 2010, 48, 1341-1349. [CrossRef]

49. Katanić Stanković, J.S.; Srećković, N.; Mišić, D.; Gašić, U.; Imbimbo, P.; Monti, D.M.; Mihailović, V. Bioactivity, biocompatibility and phytochemical assessment of lilac sage, Salvia verticillata L. (Lamiaceae)-A plant rich in rosmarinic acid. Ind. Crops Prod. 2020, 143, 111932. [CrossRef]

50. Mocan, A.; Babotă, M.; Pop, A.; Fizes, I.; Diuzheva, A.; Locatelli, M.; Carradori, S.; Campestre, C.; Menghini, L.; Sisea, C.R.; et al. Chemical constituents and biologic activities of sage species: A comparison between Salvia officinalis L., S. glutinosa L. and S. transsylvanica (Schur ex Griseb.\& Schenk) Schur. Antioxidants 2020, 9, 480.

51. Sarrou, E.; Martens, S.; Chatzopoulou, P. Metabolite profiling and antioxidative activity of Sage (Salvia fruticosa Mill.) under the influence of genotype and harvesting period. Ind. Crops Prod. 2016, 94, 240-250. [CrossRef]

52. Zengin, G.; Senkardes, I.; Mollica, A.; Picot-Allain, C.M.N.; Bulut, G.; Dogan, A.; Mahomoodally, M.F. New insights into the in vitro biological effects, in silico docking and chemical profile of clary sage-Salvia sclarea L. Comput. Biol. Chem. 2018, 75, 111-119. [CrossRef] 
53. Cvetkovikj, I.; Stefkov, G.; Acevska, J.; Stanoeva, J.P.; Karapandzova, M.; Stefova, M.; Dimitrovska, A.; Kulevanova, S. Polyphenolic characterization and chromatographic methods for fast assessment of culinary Salvia species from South East Europe. J. Chromatogr. A 2013, 1282, 38-45. [CrossRef]

54. Šulniūte, V.; Pukalskas, A.; Venskutonis, P.R. Phytochemical composition of fractions isolated from ten Salvia species by supercritical carbon dioxide and pressurized liquid extraction methods. Food Chem. 2017, 224, 37-47. [CrossRef]

55. Kindl, M.; Blažeković, B.; Bucar, F.; Vladimir-Knežević, S. Antioxidant and anticholinesterase potential of six Thymus species. Evid. Based Complement. Altern. Med. 2015, 2015, 403950. [CrossRef]

56. Schlesier, K.; Harwat, M.; Böhm, V.; Bitsch, R. Assessment of antioxidant activity by using different in vitro methods. Free Radic. Res. 2002, 36, 177-187. [CrossRef] [PubMed]

57. Orhan, I.; Kartal, M.; Naz, Q.; Ejaz, A.; Yilmaz, G.; Kan, Y.; Konuklugil, B.; Şener, B.; Iqbal Choudhary, M. Antioxidant and anticholinesterase evaluation of selected Turkish Salvia species. Food Chem. 2007, 103, 1247-1254. [CrossRef]

58. Boukhary, R.; Raafat, K.; Ghoneim, A.I.; Aboul-Ela, M.; El-Lakany, A. Anti-inflammatory and antioxidant activities of Salvia fruticosa: An HPLC determination of phenolic contents. Evid. Based Complement. Altern. Med. 2016, 2016, 7178105. [CrossRef] [PubMed]

59. Pereira, O.R.; Catarino, M.D.; Afonso, A.F.; Silva, A.M.S.; Cardoso, S.M. Salvia elegans, Salvia greggii and Salvia officinalis decoctions: Antioxidant activities and inhibition of carbohydrate and lipid metabolic enzymes. Molecules 2018, 23, 3169. [CrossRef] [PubMed]

60. Brindisi, M.; Bouzidi, C.; Frattaruolo, L.; Loizzo, M.R.; Cappello, M.S.; Dugay, A.; Deguin, B.; Lauria, G.; Cappello, A.R.; Tundis, R. New insights into the antioxidant and anti-inflammatory effects of Italian Salvia officinalis leaf and flower extracts in lipopolysaccharide and tumor-mediated inflammation models. Antioxidants 2021, 10, 311. [CrossRef]

61. Tzanova, M.T.; Gerdzhikova, M.A.; Grozeva, N.H.; Terzieva, S.R. Antioxidant activity and total phenolic content of five Salvia species from Bulgaria. Bulg. Chem. Commun. 2019, 51, 90-94.

62. Orhan, I.E.; Sezer Şenol, F.; Ercetin, T.; Kahraman, A.; Celep, F.; Akaydin, G.; Şener, B.; Doğan, M. Assessment of anticholinesterase and antioxidant properties of selected sage (Salvia) species with their total phenol and flavonoid contents. Ind. Crops Prod. 2013, 41, 21-30. [CrossRef]

63. Ekin, H.N.; Deliorman Orhan, D.; Erdoğan Orhan, I.; Orhan, N.; Aslan, M. Evaluation of enzyme inhibitory and antioxidant activity of some Lamiaceae plants. J. Res. Pharm. 2019, 23, 749-758. [CrossRef]

64. Ayala, A.; Muñoz, M.F.; Argüelles, S. Lipid peroxidation: Production, metabolism, and signalling mechanisms of malondialdehyde and 4-hydroxy-2-nonenal. Oxid. Med. Cell. Longev. 2014, 2014, 360438. [CrossRef]

65. Afonso, A.F.; Pereira, O.R.; Fernandes, Â.; Calhelha, R.C.; Silva, A.M.S.; Ferreira, I.C.F.R.; Cardoso, S.M. Phytochemical composition and bioactive effects of Salvia africana, Salvia officinalis 'Icterina' and Salvia mexicana aqueous extracts. Molecules 2019, 24, 4327. [CrossRef] [PubMed]

66. Demirezer, L.Ö.; Gürbüz, P.; Kelicen Uğur, E.P.; Bodur, M.; Özenver, N.; Uz, A.; Güvenalp, Z. Molecular docking and ex vivo and in vitro anticholinesterase activity studies of Salvia sp. and highlighted rosmarinic acid. Turk. J. Med. Sci. 2015, 45, 1141-1148. [CrossRef] [PubMed]

67. El-Tantawy, W.H.; Temraz, A. Management of diabetes using herbal extracts: Review. Arch. Physiol. Biochem. 2018, 124, 383-389. [CrossRef] [PubMed]

68. Assefa, A.T.; Yang, E.-Y.; Chae, S.-O.; Song, M.; Lee, M.; Cho, M.-C.; Jang, S. Alpha glucosidase inhibitory activities of plants with focus on common vegetables. Plants 2020, 9, 2. [CrossRef]

69. Berlanga-Acosta, J.; Guillén-Nieto, G.; Rodríguez-Rodríguez, N.; Bringas-Vega, M.L.; García-Del-Barco-Herrera, D.; Berlanga-Saez J.O.; García-Ojalvo, A.; Valdés-Sosa, M.J.; Valdés-Sosa, P.A. Insulin resistance at the crossroad of Alzheimer disease pathology: A review. Front. Endocrinol. 2020, 11, 560375. [CrossRef]

70. Butterfield, D.A.; Halliwell, B. Oxidative stress, dysfunctional glucose metabolism and Alzheimer disease. Nat. Rev. Neurosci. 2019, 20, 148-160. [CrossRef] 